\title{
Pseudomonas Aeruginosa Induced Cell Death in Acute Lung Injury and Acute Respiratory Distress Syndrome
}

\author{
Rushikesh Deshpande ${ }^{1}$ and Chunbin Zou ${ }^{2, *(D)}$ \\ 1 Department of Environmental and Occupational Health, Graduate School of Public Health, \\ University of Pittsburgh, Pittsburgh, PA 15213, USA; rhd10@pitt.edu \\ 2 Division of Pulmonary, Allergy and Critical Care Medicine, University of Pittsburgh, Pittsburgh, \\ PA 15213, USA \\ * Correspondence: zouc@upmc.edu; Tel.: +1-(412)-624-4404
}

Received: 6 July 2020; Accepted: 23 July 2020; Published: 28 July 2020

\begin{abstract}
Pseudomonas aeruginosa is an important opportunistic pathogen responsible for the cause of acute lung injury and acute respiratory distress syndrome. P. aeruginosa isthe leading species isolated from patients with nosocomial infection and is detected in almost all the patients with long term ventilation in critical care units. P. aeruginosa infection is also the leading cause of deleterious chronic lung infections in patients suffering from cystic fibrosis as well as the major reason for morbidity in people with chronic obstructive pulmonary disease. P. aeruginosa infections are linked to diseases with high mortality rates and are challenging for treatment, for which no effective remedies have been developed. Massive lung epithelial cell death is a hallmark of severe acute lung injury and acute respiratory distress syndrome caused by P. aeruginosa infection. Lung epithelial cell death poses serious challenges to air barrier and structural integrity that may lead to edema, cytokine secretion, inflammatory infiltration, and hypoxia. Here we review different types of cell death caused by P. aeruginosa serving as a starting point for the diseases it is responsible for causing. We also review the different mechanisms of cell death and potential therapeutics in countering the serious challenges presented by this deadly bacterium.
\end{abstract}

Keywords: Pseudomonas aeruginosa; cell death; apoptosis; ferroptosis; acute lung injury/acute respiratory distress syndrome; lung infection

\section{Introduction}

Acute lung injury and acute respiratory distress syndrome (ALI/ARDS) are a severe public concern worldwide. Pneumonia from viral and bacterial infection remains a major cause of infectious death. The current pandemic of COVID-19, a viral infection caused by severe acute respiratory syndrome coronavirus 2 (SARS-CoV2), mainly causes ALI/ARDS and affects almost all countries worldwide. More than 10 million patients have been diagnosed with COVID-19 with half of million deaths, and the numbers of confirmed cases and deaths are continuously increasing [1]. Viral infection destroys host defense with exhausted immune response, that is easily followed by a secondary bacterial infection. The secondary bacterial infection always renders poor prognosis of the patients. Among the microbial pathogens involving secondary infection, Pseudomonas aeruginosa, a Gram-negative rod-shaped bacterium is the leading opportunistic pathogen isolated from patients with nosocomial infection. P. aeruginosa is present in the respiratory tract of many of the patients with long-term ventilation more than 7 days [2]. It is also the leading cause of deleterious chronic lung infections in patients suffering from cystic fibrosis (CF) [3]. P. aeruginosa infection is the major reason for morbidity 
in people with chronic obstructive pulmonary disease (COPD) as well [4]. Patients with viral infection, trauma, and cancer leads to host immunosuppression that largely enhances secondary infection with P. aeruginosa. P. aeruginosa is in most of the cases multi-drug resistant and no effective cure has been developed. Diseases linked with P. aeruginosa infection display high mortality rates and are particularly challenging for treatment in patients with compromised immunity [2].

P. aeruginosa is able to adapt to a specific functional role to escape the host defense using highly complex intracellular and intercellular signaling networks. Besides, P. aeruginosa releases a large number of virulence effectors $[5,6]$. This adaptive ability however has variances according to the types of clones and strains in the P. aeruginosa population worldwide [7].The Pathogenicity of P. aeruginosa is a result of long-time adaption and evolution. Pathological changes include inflammatory response, cytokine secretion, immune cell infiltration, air-blood barrier dysfunction, leakiness, and cell death.

Once $P$. aeruginosa enters into the airway tract, the bacteria replicate and colonize in the lumen of the airway and alveolar sacs. Part of the bacteria will be engulfed and cleared by lung residential macrophages. Meanwhile, P. aeruginosa activated macrophages release inflammatory factors, result in immune cell infiltration, and subsequent hyper-reacted cytokine storm may damage the respiratory system. On the other side, part of the bacteria will invade into lung epithelial cells through the damaged physical protection barrier of mucin or surfactant films. The bacteria adhere on the surface of epithelial cell membrane and penetrate the membrane to replicate and colonize in the cells [8-12]. The flagella and Type IV pili (TFP) play the role of adhesins for host cells [9]. Other adhesins such as cup fimbrial adhesins [13], lectins PA-IL (LecA) and PA-IIL (LecB) [14] have also been identified. In the study by Hayashi N. et al. [15], it was observed that the bacteria are associated with Caco-2 cells even in the absence of intact pili, suggesting that $P$. aeruginosa can bind to Caco-2 cells using other adhesion systems. Firstly, the replication and colonization of the invaded bacteria may physically damage the integrity of the lung epithelial cells. Secondly, the bacteria cause host inflammatory response via multiple channels of molecular mechanisms that induce lung epithelial cell death. Furthermore, P. aeruginosa may directly release a number of toxins that directly destroy cellular membranes to lead to cell death. In addition, the dead cells and debris may release toxic cellular components that may further augment inflammation and autoimmune responses. P. aeruginosa infection mediated lung epithelial cell death destroys the integrity of the air-blood barrier, and leads to leaks and edema, that will attract peripheral circulating neutrophils, microphages, and lymphocyte infiltration and enhance inflammatory response. Therefore, P. aeruginosa mediated lung epithelial cell death is a major mechanism in the pathogenesis of ALI/ARDS. Our understanding on the underlying molecular mechanisms of P. aeruginosa induced lung epithelial cell death is yet to be studied for the development of an effective therapy against the pathogen and the related illnesses.

\section{Distinct Cell Death Mechanisms}

Cell death is a phenomenon exclusively existing in multicellular organisms, both in physiological processes and in responding to pathological stimulus. In order to maintain homeostasis of tissues as well as eliminate potentially harmful stimulus, cell death is a crucial process [16]. Mounting studies have dissected the molecular mechanisms of cell death and a range of distinct types of cell death have been reported. Cell death can be classified into two major classes-programmed cell death and unprogrammed cell death (Figure 1). Mechanistically, programmed cell death is subclassified as apoptotic programmed, consisting of apoptosis, and non-apoptotic programmed, consisting of ferroptosis, pyroptosis, anoikis, NETosis, and necroptosis. The unprogrammed cell death on the other hand mainly refers to necrosis as the mechanism. 


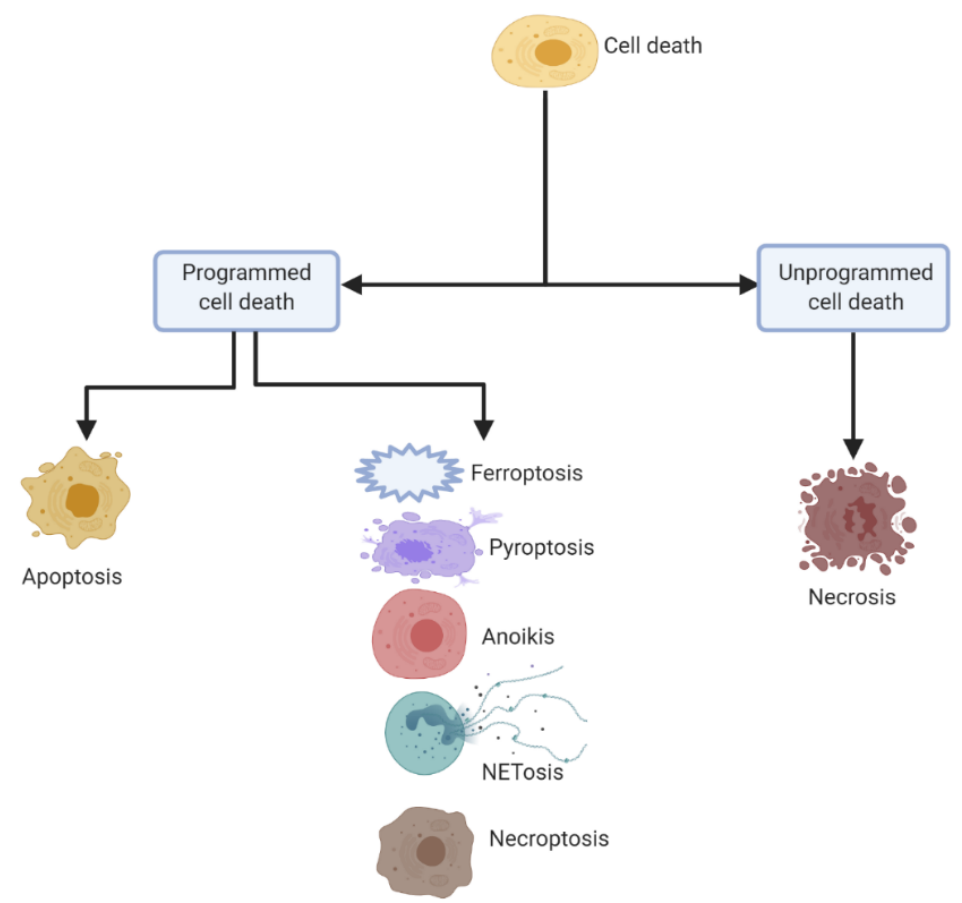

Figure 1. General classification of cell death. The broad classification is programmed and unprogrammed. The programmed cell death is subclassified as apoptotic and non-apoptotic, with apoptotic consisting of apoptosis, while non-apoptotic consisting of ferroptosis, pyroptosis, anoikis, NETosis, and necroptosis. Unprogrammed cell death has necrosis as the mechanism (all figures were created using Biorender.com).

\subsection{Apoptosis (Figure 2a)}

Apoptosis, also called programmed cell death, is the result of an orderly cascade of a multistep enzymatic activity. Histologically, the characteristic features of apoptosis are (i) cell shrinkage, (ii) membrane blebbing, and (iii) condensation of the chromatin [17]. A molecular hallmark of apoptosis is DNA fragmentation, the nuclear genomic DNA is cleaved into $\approx 180 \mathrm{bp}$ in length. Mechanistic studies reveal that apoptosis can be classified into two distinct pathways: the intrinsic pathway and extrinsic pathway. Both the intrinsic pathway and extrinsic pathway share caspase protease activation [18]. In the extrinsic pathway, apoptosis is initiated via death receptors, a group of cellular membrane proteins including tumor necrosis factor receptor (TNFR) and Fas/CD95. Once the legitimate ligands bind to the receptors on the surface of the cellular membrane, the receptors will be activated and downstream signaling will be culminated. By interacting with Fas-associated death domain protein (FADD) and other such adaptor proteins, the Death-inducing signaling complex (DISC) activates caspase 8 , which then activates caspases 6,7 , and subsequently caspase 3 , resulting finally in proteolysis of substrate and eventual cell death [19] (Figure 2a). The intrinsic pathway, also known as the mitochondrial pathway, is activated via responding to cellular stresses. Cellular stresses activate $\mathrm{Bad} / \mathrm{Bax}$, that release cytochrome $\mathrm{C}$ from the membrane of mitochondria to activate caspase 9 , and caspase 9 cleaves caspase 3 to induce cell death [16] (Figure 2a).Apoptosis could be observed in physiological processes such as in embryonic development, and it extensively exists in the pathogenesis of various diseases as well. 

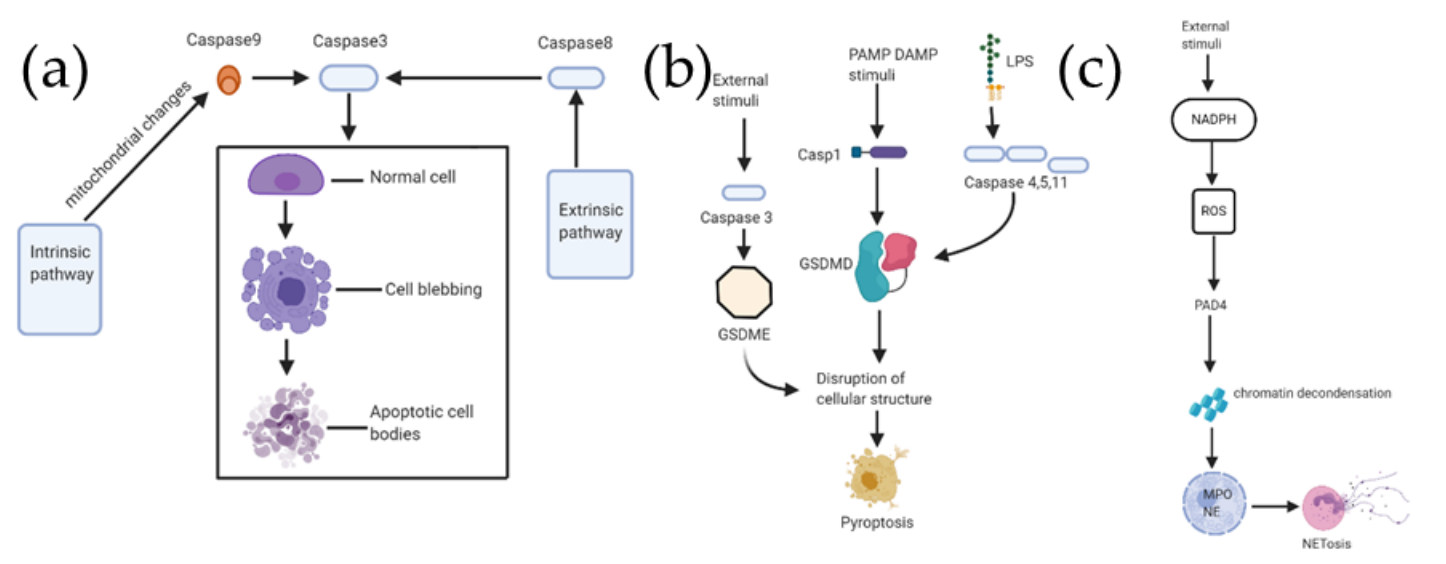

(d)

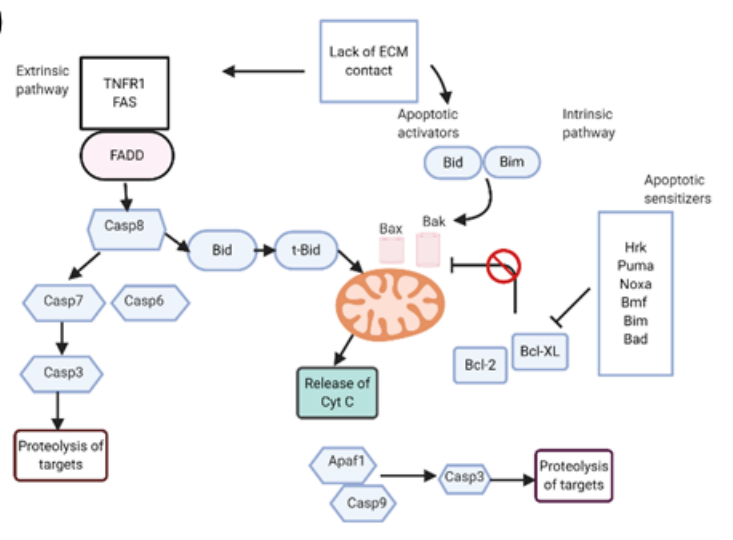

(f)

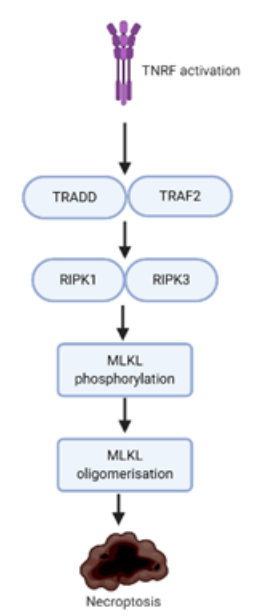

(e)

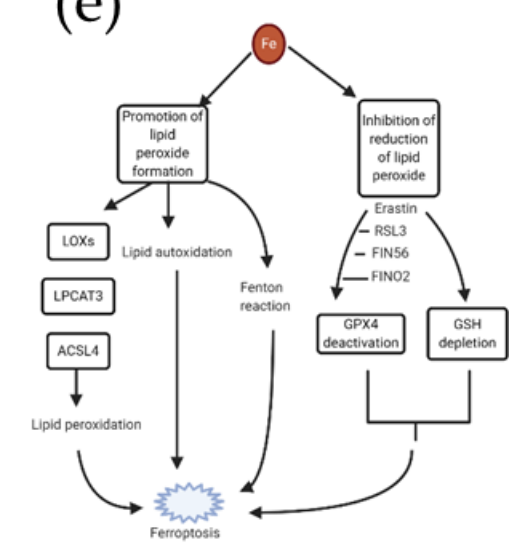

(g)

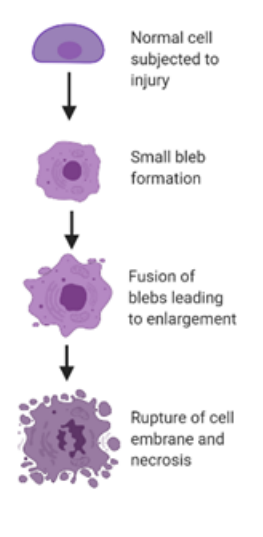

Figure 2. Schema for the mechanisms for different types of cell deaths. Part (a) displays two important pathways for apoptosis, namely intrinsic and extrinsic pathways, both converging at caspase- 3 as the executioner pathway. Part (b) shows the three underlying pathways for pyroptosis involving caspases 1,3,4,5, and 11. Part (c) is the schematic representation for NETosis. Part (d) exhibits the two pathways for anoikis, intrinsic and extrinsic, respectively. Part (e) outlines the mechanistic pathways associated with ferroptosis, promotion of lipid peroxide formation being one path and inhibition of reduction of lipid peroxide being the other. TNF/TNFR signaling pathway for necroptosis via MLKL phosphorylation is displayed in part (f). Finally, part (g) represents the different stages in a general necrosis mechanism. 


\subsection{Pyroptosis (Figure 2b)}

Pyroptosis is a type of programmed cell death involving breakage of plasma-membrane, resulting in the release of proinflammatory intracellular contents [20]. Caspases 1, 4, 5, and 11 play an important role in pyroptosis [21]. Three different pathways for pyroptosis have been proposed so far(Figure 2b): the caspase 1 dependent pathway also called the canonical inflammasome pathway, the noncanonical inflammasome pathway consisting of caspases 4,5 , and 11 , and most recently proposed the caspase 3 dependent pathway [21,22].In the canonical inflammasome pathway, intracellular pattern recognition receptors (PRR) receive signal stimulation in the form of pathogen-associated molecular patterns (PAMPs) and danger-associated molecular patterns (DAMPs). Subsequently, the inflammatory body is assembled and an intracellular macromolecular protein complex is produced, leading to the activation of caspase 1 , which thereby causes secretion ofIL-1 $\beta$ and IL-18 on one hand, and cleavage of gasdermin-D (GSDMD) to generate two types of ends-reactive amino $(\mathrm{N})$ and carboxyl (C). All this leads to the destruction of cellular structure and subsequent cell lysis and cell death [21].

In the noncanonical inflammasome pathway, caspase-11, derived from mice, and caspases 4 and 5, both derived from humans, can induce pyroptosis. In this pathway, binding of the caspase to LPS occurs, leading to the cleavage of GSDMD which promotes pyroptosis [21]. The third pathway, which is caspase- 3 dependent, is similar to the canonical inflammasome pathway, with the only difference being that it involves the cleavage of gasdermin E (GSDME), instead of GSDMD. This cleavage leads to the cell structure destruction and eventual pyroptosis [21].

\subsection{NETosis (Figure 2c)}

The dynamic process of activation and release of neutrophil extracellular traps (NETs) which may result in cellular death is termed as NETosis [23]. NADPH-oxidase production of reactive oxygen species (ROS) is suggested to be the starting point of the pathway, leading to the activation of protein-arginine deiminase 4 (PAD4), an enzyme responsible for chromatin decondensation in the neutrophil nucleus. The subsequent rupture of the nuclear envelope occurs when myeloperoxidase (MPO) and neutrophil elastase (NE) enters the nucleus. Suicidal NETosis and vital NETosis are the two forms, with the key differences being in the stimuli, timing, and the end result (Figure 2c). NETosis is observed in many cases of infection, and it is also observed in no-infectious conditions.

\subsection{Anoikis (Figure 2d)}

Anoikis is a particular type of apoptosis occurring in the cells, either in absence of attachment to extracellular matrix (ECM) or the cells getting adhered to an inappropriate location [19]. Two apoptotic pathways are responsible for inducing the anoikis program, namely the intrinsic pathway, involving the perturbation of mitochondria, and the extrinsic pathway, consisting of cell surface death receptors getting triggered. The proteins of the Bcl-2 family are critical to both the pathways [19]. There are three categorizations of Bcl-2 proteins: anti-apoptotic proteins, multidomain pro-apoptotic proteins, and BH3-only proteins, which are also pro-apoptotic. Anoikis shares common downstream pathways of apoptosis (Figure 2d). In the intrinsic pathway, BH3-only proteins, including Bim, Hrk, Bmf, Bad, Bik, Puma, and Noxa, promote the activation of Bax/Bak. Among them, the direct promotion is done by Bid and Bim (activators), while the other members also known as sensitizers, promote indirectly by counteracting the anti-apoptotic functions of $\mathrm{Bcl}-2$. The release of cytochrome $\mathrm{c}$ to the cytoplasm is the final step, leading to apoptosome formation, and thereby activation of executioner caspases [19]. The extrinsic pathway, which is the death receptor pathway, is initiated by members of TNFR, such as Fas and TNFR1, which leads to the apoptotic signal transductions.

\subsection{Ferroptosis (Figure 2e)}

Ferroptosis can be defined as a death program which is executed by selective oxidation of arachidonic acid-phosphatidylethanolamines (AA-PE) by 15-lipoxygenases [24]. It has been identified 
that the substrates and the products of this process are arachidonoyl-phosphatidylethanoamine (AA-PE) and 15-hydroperoxy-AA-PE (15-HOO-AA-PE), respectively $[25,26]$. Since lipid peroxide is an important participant in ferroptosis (Figure 2e), this categorizes two processes, one which promotes lipid peroxide formation and thereby ROS generation, and other which inhibits the reduction of lipid peroxides [27].

Inhibition of reduction of lipid peroxide is achieved either by deactivating GPX4 or by depleting its cofactor glutathione (GSH) $[28,29]$. The inhibitors which directly or indirectly deactivate GPX4 are Erastin, RSL3, FIN56, and FINO2, while GSH depletion is done by Erastin alone [27]. On the other hand, the enzymes which promote the lipid peroxide formation are lysophosphatidylcholine acyltransferase 3 (LPCAT3), lipoxygenases (LOXs), and acyl-CoA synthetase long-chain family 4 (ACSL4) [25,30-33]. Additionally, production of ROS by fenton reaction and lipid autoxidation are also the pathways for ferroptosis [34,35].

\subsection{Necroptosis (Figure 2f)}

Necroptosis is a programmed form of necrosis [36]. Distinct with unregulated necrosis, cells can execute necrosis in a programmed manner independent of caspase activation. The tumor necrosis factor/tumor necrosis factor receptor (TNF/TNFR) signaling pathway has revealed to initiate necroptosis. Activation of TNFR signals TNFR-associated death protein (TRADD) and TNFR-associated factor 2 (TRAF2) that recruits Receptor-interacting protein kinase 1/ Receptor-interacting protein kinase 3 (RIPK1/RIPK3) to form a necrosome. The necrosome promotes mixed lineage kinase domain-like protein (MLKL) phosphorylation, allowing the MLKL to insert into and permeabilize plasma membranes and organelles that result in cell death (Figure 2f).

\subsection{Necrosis (Figure 2g)}

Necrosis is a form of cell death due to an external or internal injury that results in a premature death of the cell in the living tissues with autolysis. A variety of injury factors including microbial infection, toxins, or trauma induce necrosis by a digestion of the cell components. Necrosis is detrimental and can be fatal. Morphologically, necrosis is characterized by the nuclei of the cells fading away and shrinking and disruption of the membrane of the cells or organelle. It is in general believed that necrosis is an unregulated process (Figure 2g).

\section{P. aeruginosa Induced Lung Epithelial Cell Death}

\subsection{P. aeruginosa Triggers Apoptosis in Lung Epithelial Cells (Figure 3a)}

P. aeruginosa uses distinct mechanisms for initiating the cell death of the infected host cells [37]. The most studied cell death is apoptosis (Table 1). A well-studied paradigm is the extrinsic apoptotic pathway Fas (CD95)/Fas ligand signaling in lung epithelial cells. Following the infection of epithelial cells, either by in vitro or in vivo route, P. aeruginosa causes an upregulation of Fas/Fas ligand on the cell surface [38], an endogenous receptor ligand pair considered to be one of the most important ones responsible for the triggering of apoptosis. Bacteria derived type III secretion system (T3SS) upregulates the Fas/Fas ligand pair in P. aeruginosa infected cells and bacteria who do not possess a functional T3SS almost fail to cause apoptosis in epithelial cells. Upon upregulation, ligation of Fas by Fas ligand leads to induction of caspase 8 and caspase 3 activation, release of mitochondrial cytochrome $\mathrm{C}$, as well asc-Jun $\mathrm{N}$-terminal protein kinase(JNK) activation [37]. It is also found that reactive oxygen intermediates seem to be crucial for inducing P. aeruginosa triggered death [39]. Genetic studies using cells or mice genetically deficient for functional Fas or Fas ligand have shown the significance of the Fas/Fas ligand system for P. aeruginosa triggered cell death [38]. There was no response to P. aeruginosa infections resulting in induction of apoptosis in epithelial cells obtained in vivo from mice deficient in Fas or Fas ligand or ex vivo fibroblasts deficient in either Fas or Fas ligand. Apoptosis of lung epithelial cells upon getting infected with $P$. aeruginosa forms a crucial part of the host defense against infection 
from P. aeruginosa, which is contrary to the role of apoptosis due to infection from some other bacteria such as Shigella flexneri [37]. This was demonstrated by comparative in vivo pulmonary infection of Fas or Fas ligand deficient mice and normal mice. The former rapidly developed sepsis and died, while the latter completely cleared the infection within a period of few days. Another study has also demonstrated the protective effect of apoptosis triggered by bacteria [40]. The finding of that study is that a ced 3 and ced 4 regulated death of worm gonad cells is triggered when the worm Caenorhabditis elegans (C. elegans) is infected with Salmonella Typhimurium (S. typhimurium). However, apoptosis inhibition in those cells caused by mutations of ced3 and ced4, respectively, leads to hyper-sensitization of C. elegans to the S. typhimurium infection [37].

Table 1. A summary of different mechanisms underlying the different types of epithelial cell death.

\begin{tabular}{|c|c|c|c|}
\hline Type of Cell Death & Description & Mechanism & Reference Numbers \\
\hline Apoptosis & $\begin{array}{l}\text { CD95/CD95-ligand system } \\
\text { for } P \text {. aeruginosa triggered } \\
\text { apoptosis }\end{array}$ & $\begin{array}{c}\text { P. aeruginosa causes an } \\
\text { up-regulation of } \\
\text { CD95/CD95ligand on the cell } \\
\text { surface, responsible for the } \\
\text { triggering of apoptosis }\end{array}$ & [37-40] \\
\hline Apoptosis & $\begin{array}{l}\text { Disruption of mitochondrial } \\
\text { morphology using } \\
\text { 3-oxo-C12-HSL }\end{array}$ & $\begin{array}{l}\text { Quorum sensing molecule } \\
\text { 3-oxo-C12-HSL activates the } \\
\text { apoptosis by disrupting the } \\
\text { mitochondrial structure, } \\
\text { attenuating cellular respiration } \\
\text { and inducing ROS generation }\end{array}$ & [41] \\
\hline Apoptosis & $\begin{array}{l}\text { Caspase 3-caspase } \\
\text { 8-mediated apoptosis }\end{array}$ & $\begin{array}{l}\text { Necrosis factor receptor } 1 \\
\text { expelled into the disordered } \\
\text { lipid phase triggers cell death }\end{array}$ & [42] \\
\hline Apoptosis & $\begin{array}{l}\text { Apoptosis due to } \\
\text { Cx43-mediated cell-to-cell } \\
\text { communication }\end{array}$ & $\begin{array}{l}\text { Cx43-mediated gap junctional } \\
\text { communication enhances } \\
\text { apoptosis in PAO1-infected } \\
\text { airway epithelial cells, while on } \\
\text { the other hand JNK signaling } \\
\text { inhibits Cx43 function }\end{array}$ & [43] \\
\hline Pyroptosis & $\begin{array}{l}\text { PAO1 flagellin induced } \\
\text { CASP1-dependent } \\
\text { neutrophil pyroptosis }\end{array}$ & $\begin{array}{l}\text { PAO1-induced pyroptosis } \\
\text { depends on NLRC4 and Toll-like } \\
\text { receptor } 5 \text { (TLR5) in neutrophils }\end{array}$ & [44] \\
\hline NETosis & $\begin{array}{l}\text { Type I interferon } \\
\text { associated NETosis }\end{array}$ & $\begin{array}{l}\text { Excessive activation of } \\
\text { neutrophils by type I IFNs } \\
\text { causes aboost in NETosis which } \\
\text { triggers biofilm formation by } P \text {. } \\
\text { aeruginosa, thereby supporting } \\
\text { its persistence in the } \\
\text { infected lung. }\end{array}$ & [45-48] \\
\hline NETosis & $\begin{array}{c}\text { NADPH } \\
\text { Oxidase-Dependent NETosis }\end{array}$ & $\begin{array}{l}\text { Increase in } \mathrm{pH} \text { in neutrophils } \\
\text { stimulates Nox activity and ROS } \\
\text { production requiredl } \\
\text { for NETosis }\end{array}$ & [49] \\
\hline Anoikis & $\begin{array}{l}\text { Pseudomonas aeruginosa ExoT } \\
\text { induced atypical anoikis }\end{array}$ & $\begin{array}{l}\text { GAP domain of ExoT is } \\
\text { responsible for triggering the } \\
\text { mitochondrial intrinsic pathway } \\
\text { of anoikis apoptosis }\end{array}$ & [50-52] \\
\hline Ferroptosis & $\begin{array}{l}\text { P. aeruginosa produced } \\
\text { biofilm induces ferroptosis }\end{array}$ & $\begin{array}{c}\text { Caused by enhancing expression } \\
\text { of pLoxA as well as oxidising } \\
\text { host cell AA-PE to } \\
\text { 15-HOOAA-PE }\end{array}$ & [24] \\
\hline
\end{tabular}


P. aeruginosa may induce extrinsic apoptosis without ligand binding by directly polymerizing the death receptors within lipid rafts, that process activates the death receptor. A recent study reported that the quorum-sensing autoinducers $\mathrm{N}$-(3-oxo-dodecanoyl) homoserine lactone in P. aeruginosa triggers significant cell death in B-lymphocytes, T-lymphocytes, dendritic cells, microphages, and monocytes. N-(3-oxo-dodecanoyl) homoserine lactone is able to incorporate into the host cell plasma membrane, plasma membrane lipid components containing cholesterol, sphingomyelin, and 1-2-dioleoyl-sn-glycero-3-phosphocholine (DOPC) efficiently retain 3-oc [42]. Addition of cholesterol inhibitor methyl- $\beta$-cyclodextrin dissolved cholesterol into the solution, thus disrupted the retention of 3-oc in the lipid domains. Retention of 3-oc in the plasma membrane dramatically changed the appearance of the presumed solid ordered lipid domains with a clear dissolution of the elevated plains of lipid domains to form smaller sized lipid rafts and collapse of the cholesterol and sphingomyelin-rich lipid domains, which was unrelated to membrane leakiness. However, domains formed with a mixture of DOPC and DPPG, unrelated to lipid rafts, were minimally affected. This event expels TNFR1 into the disordered lipid phase for its spontaneous trimerization without its ligand and drives Caspase 8-Caspase 3 mediated apoptosis [42].

$P$. aeruginosa activates cell surface receptors, thereby eliciting a cascade for intracellular signaling [43]. This leads to an increase in the communication at gap junction of the protein Cx43. It is observed that the expression of Cx43 displayed regulation in opposite directions exerted by JNK and p38 MAPKs. JNK inhibitor caused an increase in the PAO1-induced apoptosis, but the apoptosis was prevented by lentiviral expression of a Cx43-specific short hairpin RNA. Interestingly it is found that JNK activity undergoes upregulation by pharmacological restriction of CFTR in Calu-3 cells, however, when the CF airway cell line (CF15 cells) is corrected by adenoviral expression of CFTR, it causes a reduction in this MAPK being activated. This CTFR inhibition is also linked to the downregulation of Cx43 and thereby reduction in apoptosis. These results indicate that Cx43 expression forms a part of the response of airway epithelial cells by maintaining a balance of survival and apoptosis [43].

Another study demonstrated that $P$. aeruginosa induces the intrinsic apoptotic pathway via mitochondria. It has identified an important pathway responsible for the pathogenesis of lung injury caused by a P. aeruginosa linked virulence factor [41]. 3-oxo-C12-HSL is a principal quorum sensing molecule of $P$. aeruginosa, which causes disruption of mitochondrial morphology and promotes mitochondrial DNA oxidative injury. 3-oxo-C12-HSL downregulates the expression of peroxisome proliferator-activated receptor- $\gamma$ coactivator- $1 \alpha$ (PGC- $1 \alpha)$, which is responsible for regulating biogenesis of mitochondria, acting as an antioxidant defense, as well as playing a role in cellular respiration. Overexpression of PGC-1 $\alpha$ reduces the inhibition in cellular respiration produced due to 3-oxo-C12-HSL. It is also observed that the pharmacologic activation of PGC- $1 \alpha$ causes restoration of barrier integrity in cells treated with 3-oxo-C12-HSL.

P. aeruginosa mediated apoptosis is stringently regulated in a few ways. Oral bacteria may be responsible for modulating the adhesion and invasion of respiratory pathogens to epithelial cells $[53,54]$. The presence of oral pathogenic bacteria leads to more P. aeruginosa infected epithelial cells via augmented mucosal surface invasion and lung epithelial cell apoptosis. Furthermore, oral as well as respiratory bacteria appear to induce the proinflammatory cytokines release from respiratory epithelial cell lines in vitro [54]. Oral bacteria may be responsible for altering the local microenvironment, thereby facilitating the onset and/or progression of respiratory disease in susceptible individuals [54].

It has been demonstrated that physiological levels of acidosis cause enhancement of epithelial cell cytotoxicity during a P. aeruginosa infection [55]. It has been shown in the study that the increase in epithelial cytotoxicity during acidosis is caused due to reduction in antimicrobial activity. Additionally, it has also been established that the epithelial-derived bactericidal activity is dependent on $\mathrm{pH}$. Overall, these findings have provided key insights into the contribution of changes in extracellular $\mathrm{pH}$ to the pathogenesis of P. aeruginosa infections. 


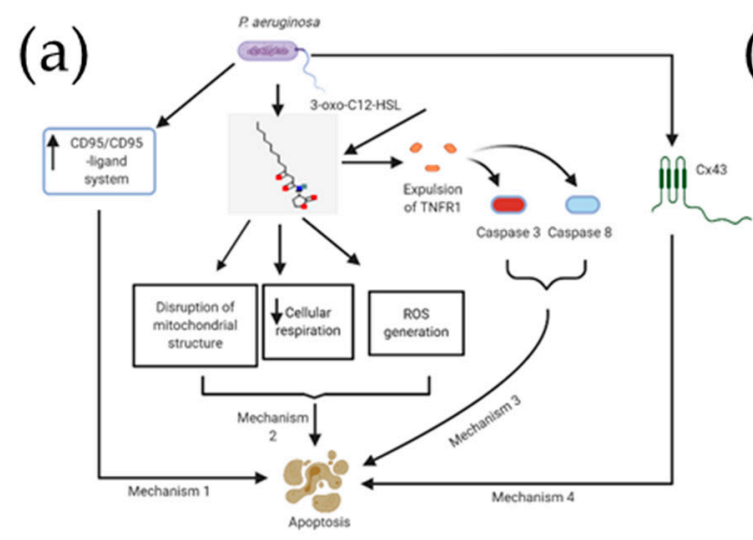

(b)
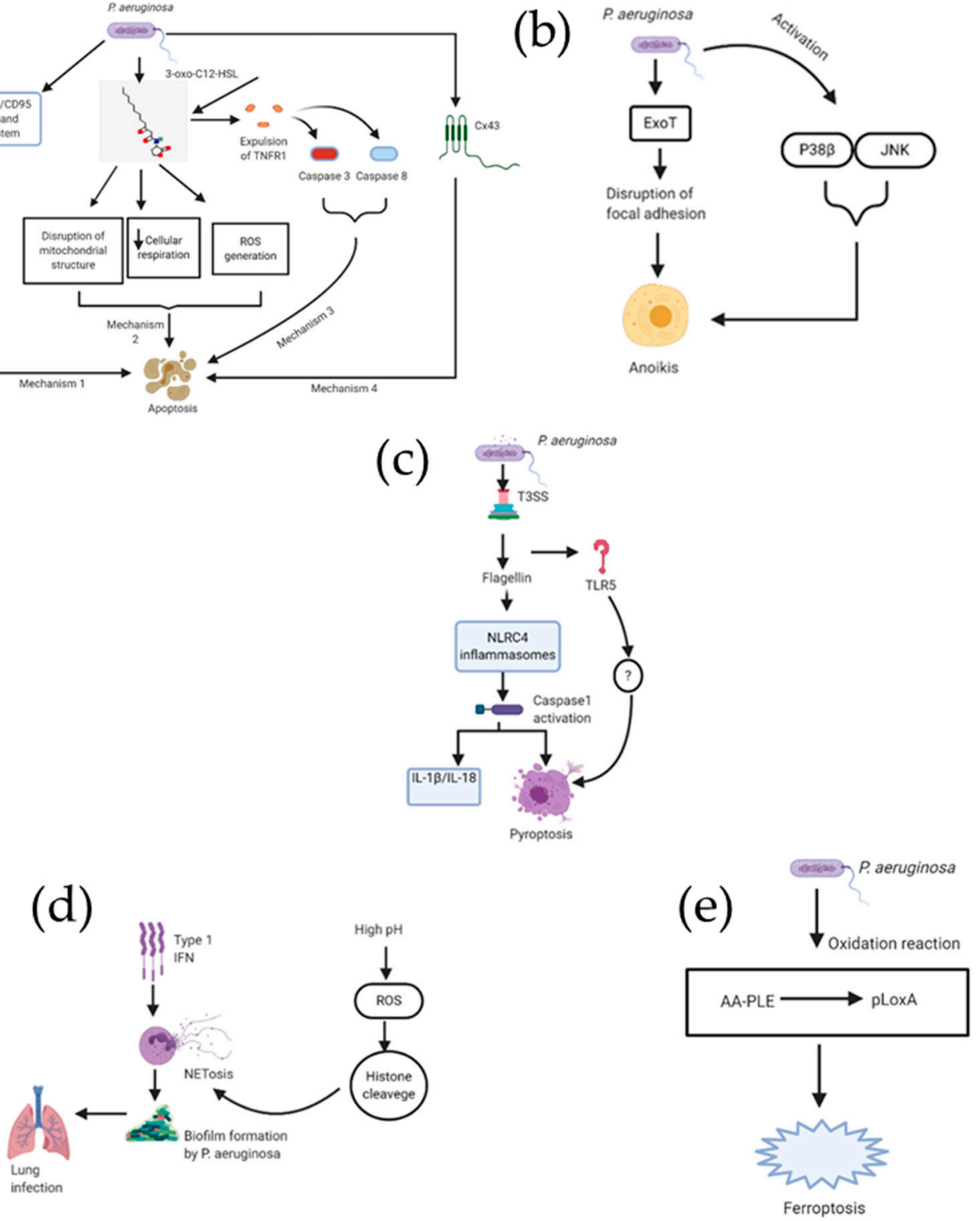

Figure 3. Schematic representation for the different cell death mechanisms caused due to $P$. aeruginosa infection. Part (a) consists of four important pathways for apoptosis, part (b) displays ExoT induced as well as activated P38-JNK induced anoikis, part (c) focuses on the two pathways associated with pyroptosis, part (d) is a cartoon representation of NEtosis pathway. Finally, part (e) is a single mechanism for $P$. aeruginosa induced ferroptosis involving peroxide formation and reactive oxygen species (ROS) generation, since ferroptosis is a newer cell death mechanism still being investigated for additional pathways.

\subsection{Epithelial Anoikis Caused by P. aeruginosa Infection (Figure 3b)}

It has been reported that the GAP as well as the ADPRT domains of Exoenzyme T (ExoT) derived from $P$. aeruginosa contribute to ExoT-induced apoptosis in epithelial cells [50]. Crk adaptor protein gets transformed into a cytotoxin due to the ADPRT domain activity, inducing atypical anoikis apoptosis due to interference in the signaling of integrin survival [51]. However, the mechanism for the GAP-induced apoptosis was unknown until a more recent study shed light on this. It has been demonstrated in this study that the GAP domain of ExoT is responsible for triggering the mitochondrial intrinsic pathway of apoptosis [52]. The data from the study shows that intoxication of GAP leads to (i) Bax, $\mathrm{Bid}$, and to a lesser extent Bim, getting activated and accumulated in the mitochondrial membrane; 
(ii) mitochondrial membrane losing its potential as well as cytochrome c release; (iii) activation of the initiator caspase-9 getting activated, resulting in the activation of the executioner caspase- 3 thereby culminating in cell demise [52].

\subsection{P. aeruginosa Induced Pyroptosis (Figure 3c)}

Neutrophil pyroptosis is caused due to acute $P$. aeruginosa infection via inflammasome signaling. It has been reported that flagellin within $P$. aeruginosa and mitochondrial reactive oxygen species (ROS) cause neutrophil pyroptosis upon acute lung infection through CASP1-dependent signaling in Nox2 mice, resulting in enhanced lung inflammation and injury [44]. It has been demonstrated that PAO1-induced pyroptosis depends on NLRC4 and Toll-like receptor 5 (TLR5) in neutrophils. The authors suggest that mitochondrial ROS plays a role as a bridge between NOX2-mediated signaling and inflammasome activation in neutrophils, caused due to bacterial infection.

\subsection{P. aeruginosa Associated NETosis (Figure 3d)}

Type I interferons (IFNs) regulate neutrophil activity, and therefore act as the first line of anti-bacterial host defense $[45,46]$. Infections with bacteria, such as P. aeruginosa, are often linked to the increase in type I IFN signaling in lung epithelial cells [47]. It has been demonstrated that type I IFN-mediated activation of neutrophils in lungs causes increase in NETosis, leads to the prominent tissue damage, and supports biofilm formation by P. aeruginosa and its persistence in the lung [48]. The role of $\mathrm{PH}$ in mediation of NETosis is also an important aspect [49]. It shows that increasing $\mathrm{pH}$ in neutrophils caused stimulation in Nox activity and ROS production, both of which are essential agonist-induced Nox-dependent NETosis. At higher $\mathrm{pH}$, neutrophil proteases, considered to be important for NETosis [50,51], could better cleave the histones after entering NETotic nuclei. Hence, high $\mathrm{pH}$ enables NETosis while low $\mathrm{pH}$ suppresses NETosis. It is also mentioned in the study that compounds such as sodium bicarbonate and THAM, which are clinically used, effectively increase $\mathrm{pH}$ and promote NETosis, which suggests the possible role of these compounds in correcting defective NETosis in vivo.

\subsection{Epithelial Ferroptosis in Context of P. aeruginosa (Figure 3e)}

In a new study, it has been reported that a mutant of $P$. aeruginosa producing biofilm induces ferroptosis in human bronchial epithelial (HBE) cells [24]. This is done by enhancing expression of pLoxA as well as oxidizing host cell AA-PE to 15-HOOAA-PE. It was observed that clinical $P$. aeruginosa isolates from patients suffering from prolonged lower respiratory infection resulted in pLoxA-dependent ferroptosis of HBE cells. High levels of 15-HOO-AA-PE in airway tissues from cystic fibrosis patients were detected using global redox phosphorlipidomics. However, in CF patients without $P$. aeruginosa in airway cultures, such elevated levels were not detected. Based on the assumption that disruption of epithelial barrier and immune-regulatory functions play a key role for pathogenesis of P. aeruginosa-related respiratory diseases, pLoxA as a potential new therapeutic target was proposed.

\section{Cell Death Mediation and Therapeutic Strategies}

\subsection{Role of IL-15 in Apoptosis Prevention}

Interleukin-15 (IL-15) belongs to the $\gamma$-chain family of cytokines, with IL-2, IL-4, IL-7, IL-9, and IL-21 being the other members [56-60]. IL-15 is unique among all of its family members on account of its pattern of receptor expression, which is observed in DC, NK, and CD8 T cells [61]. Due to this fact, IL-15 performs coordination of the response of these innate and adaptive immune cells for protecting the host [62-66]. IL-15 blocks sepsis-induced apoptosis in NK cells, dendritic cells, and CD8 T cells [61]. Sepsis induced gut epithelial apoptosis also decreases on account of IL-15. Furthermore IL-15 therapy increases antiapoptotic Bcl-2 and decreases proapoptotic Bim and PUMA. IL-15 increases circulating 
IFN- $\gamma$, along with the percentage of NK cells that produced IFN- $\gamma$. Lastly, IL-15 is responsible for increase in survival in both models of cecal ligation and puncture and P. aeruginosa pneumonia. Thus IL-15 is a potential novel therapy for the deadly P. aeruginosa caused disease.

\subsection{Platelets Inhibit Epithelial Cell Apoptosis}

A study has found that platelets are responsible for attenuating pathogen induced lung injury and protecting from lung epithelial apoptosis [7]. Platelet deficiency was identified to associate with severe disruption of alveolar-capillary barrier in live bacteria as well as bacterial exoproduct models representing P. aeruginosa infection. Platelets play a role in alveolar-capillary barrier homeostasis, but can also enter the airspace and release protective factors at the time of infection, thereby limiting alveolar epithelial cell death and reducing the further effect of lung injury. Lastly, the study also identified a potential protective role for platelet granule factors against lung injury triggered by pathogen as well as showed that platelet releasates are responsible for attenuating in vitro lung epithelial cell death as well as disrupting, independent of the whole platelets, the lung vascular barrier in mice deficient in platelets.

\subsection{Mediation of Epithelial Cell Death in P. aeruginosa Pneumonia by Morf4l1}

Mortality factor 4 like 1 (Morf4l1) is a protein playing a role in chromatin remodeling [67]. Its fundamentally low level of expression in the lung is on account of its short life via continuous ubiquitin proteasomal degradation, which is mediated by Fbxl18, an orphan ubiquitin E3 ligase subunit [67]. There is however an increase in the expression of Morf4l1 in humans with pneumonia and an upregulation in lung epithelia on getting exposed to P. aeruginosa or lipopolysaccharide (LPS) [67]. In a mouse model of pneumonia induced by P. aeruginosa, it was observed that Morf411 is stabilized due to acetylation that protects it from Fbxl18-mediated degradation. After the mice were infected with P. aeruginosa, overexpression of Morf4l1 enhanced lung epithelial cell death, in contrast to restored cell viability when it was depleted. A U.S. Food and Drug Administration-approved thrombin inhibitor argatroban, was identified to be a Morf411 antagonist using in-silico modeling as well as drug-target interaction studies. It was observed that Morf4l1-dependent histone acetylation, inhibited by argatroban, caused a reduction in its cytotoxicity and thereby improved the survival of mice with experimental lung injury at doses where the anticoagulant activity was none. This study uncovered a new biological mechanism, but also identified a potential molecular target for non-antibiotic pharmacological therapy in severe pulmonary infection.

\subsection{Inhibition of Cellular Apoptosis and Autophagy Due to Tremella Polysaccharides}

The endotoxin LPS derived from P. aeruginosa is able to induce apoptosis and autophagy, as well as increases the production of reactive oxygen species (ROS) in a time dependent manner in human epithelial A549 lung cancer cells [68]. It was also observed that LPS treatment suppressed sirtuin 1 (SIRT1) protein expression in the cells. The notable aspect of the study was the demonstration of SIRT1 activation due to Tremella polysaccharides activating SIRT1, resulting in an increase in the p62 expression, decrease of p53 acetylation as well as B-cell lymphoma 2-associated X protein expression, which subsequently attenuated LPS-induced apoptotic cell death and autophagy. These results open several potential avenues for treating the P. aeruginosa infection.

\section{Conclusions and Future Directions}

P. aeruginosa is a highly versatile microorganism, which continues to astonish us by evolving and acquiring new and unexplored modes of niche adaptation, lifestyle, as well as pathogenicity. A major mechanism of the pathogenicity of $P$. aeruginosa is causing host cell death. Among distinct cell death pathways that $P$. aeruginosa elicited, apoptosis is well studied. It may use a range of mechanisms to cause host cell apoptosis both in intrinsic and extrinsic apoptotic pathways. Meanwhile, a few studies focused on the regulation of $P$. aeruginosa induced apoptosis. A number of cell death pathways other 
than apoptosis have been reported (tableure 3). The importance of each pathway should be weighted in the pathogenesis of cell death by P. aeruginosa. Several attempts have been thrown into targeting P. aeruginosa induced cell death, these include IL-15, platelet factors, chromatin modulator Morf4l1, or LPS antagonists. Continued focus needs to be given on understanding the mechanisms of cell death that may lead to the identification of novel targeting therapeutics. Preclinical trials are required to verify the efficacy of the discovered targets. P. aeruginosa is the leading pathogen isolated in patients within critical care units. Secondary infection with P. aeruginosa worsens the prognosis of the patients. In the current pandemic of COVID-19, it is estimated that approximately $5 \%$ of the total patients are treated within critical care units $[69,70]$. Among these patients, sepsis has been noticed as a major contributor to the poor prognosis. The importance of the secondary infection with P. aeruginosa in the severe COVID-19 patients with long-term ventilation has yet to be understood. Prevention of the nosocomial P. aeruginosa infection may be critical to reduce the mortality of COVID-19.

Funding: This work is supported, in part, with R01 grants (HL125435 and HL142997) from National Institute of Health at The United States to C.Z.

Conflicts of Interest: The authors declare no conflict of interest.

\section{Abbreviations}

\begin{tabular}{|c|c|}
\hline AA-PE & Arachidonic acid-phosphatidylethanolamines \\
\hline ACSL4 & Acyl-CoA synthetase long-chain family 4 \\
\hline ADPRT & (ADP-ribosyl) transferase \\
\hline ALI & Acute lung injury \\
\hline ARDS & Acute respiratory distress syndrome \\
\hline BAD & BCL2 associated agonist of cell death \\
\hline BAX & Bcl-2-associated $X$ protein \\
\hline BIK & BCL2 Interacting Killer \\
\hline BIM & Bcl-2-like protein 11 \\
\hline BMF & Bcl2 Modifying Factor \\
\hline C. elegans & Caenorhabditis elegans \\
\hline CD8 & Cluster of differentiation 8 \\
\hline CD95 & Cluster of differentiation 95 \\
\hline CFTR & Cystic fibrosis transmembrane conductance regulator \\
\hline COPD & Chronic obstructive pulmonary disease \\
\hline COVID-19 & Coronavirus disease of 2019 \\
\hline CX43 & Connexin 43 \\
\hline DAMPs & Danger-associated molecular patterns \\
\hline $\mathrm{DC}$ & Dendritic cells \\
\hline DISC & Death-inducing signaling complex \\
\hline DOPC & 1-2-dioleoyl-sn-glycero-3-phosphocholine \\
\hline DPPG & 1,2-Dipalmitoyl-sn-glycero-3-phosphoglycerol \\
\hline ExoT & Exoenzyme T \\
\hline FADD & Fas-associated death domain protein \\
\hline FBXL18 & F-Box and Leucine Rich Repeat Protein 18 \\
\hline GAP & GTPase-accelerating protein \\
\hline GPX4 & Glutathione peroxidase 4 \\
\hline GSDMD & Gasdermin-D \\
\hline GSDME & Gasdermin E \\
\hline GSH & Glutathione \\
\hline HBE & Human bronchial epithelial \\
\hline HRK & Harakiri \\
\hline IFNs & Interferons \\
\hline IL-15 & Interleukin-15 \\
\hline JNK & c-Jun N-terminal kinases \\
\hline
\end{tabular}




\begin{tabular}{|c|c|}
\hline LecA & Lectins PA-IL \\
\hline LecB & Lectins PA-IIL \\
\hline LOXs & Lipoxygenases \\
\hline LPCAT3 & Lysophosphatidylcholine acyltransferase 3 \\
\hline LPS & Lipopolysaccharide \\
\hline MLKL & Mixed lineage kinase domain-like protein \\
\hline Morf411 & Mortality factor 4 like 1 \\
\hline $\mathrm{MPO}$ & Myeloperoxidase \\
\hline $\mathrm{NE}$ & Neutrophil elastase \\
\hline NK & Natural killer cells \\
\hline NLRC4 & NLR Family CARD Domain Containing 4 \\
\hline NOXA & Phorbol-12-myristate-13-acetate-induced protein 1 \\
\hline P. aeruginosa & Pseudomonas aeruginosa \\
\hline PAMPs & Pathogen-associated molecular patterns \\
\hline PAMPs & Pathogen-associated molecular patterns \\
\hline PGC- $1 \alpha$ & Proliferator-activated receptor- $\gamma$ coactivator- $1 \alpha$ \\
\hline PRR & Pattern recognition receptors \\
\hline PUMA & p53 upregulated modulator of apoptosis \\
\hline RIPK1 & Receptor-interacting protein kinase 1 \\
\hline RIPK3 & Receptor-interacting protein kinase 3 \\
\hline ROS & Reactive oxidation species \\
\hline SARS-CoV2 & Severe acute respiratory syndrome coronavirus 2 \\
\hline SIRT1 & Sirtuin 1 \\
\hline T3SS & Type III secretion system \\
\hline TFP & Type IV pili \\
\hline THAM & Tris-hydroxymethyl aminomethane \\
\hline TLR5 & Toll-like receptor 5 \\
\hline TNF & Tumor necrosis factor \\
\hline TNFR & Tumor necrosis factor receptor \\
\hline TRADD & TNFR-associated death protein \\
\hline TRAF2 & TNFR-associated factor 2 \\
\hline 3-oc & (3-oxo-dodecanoyl) homoserine lactone \\
\hline
\end{tabular}

\section{References}

1. COVID-19 Map. Available online: https://coronavirus.jhu.edu/map.html (accessed on 6 July 2020).

2. Vincent, J. International Study of the Prevalence and Outcomes of Infection in Intensive Care Units. JAMA 2009, 302, 2323. [CrossRef] [PubMed]

3. Høiby, N.; Frederiksen, B. Microbiology of cystic fibrosis. In Cystic Fibrosis; Arnold Publishers-International Book and Journal Publishers: London, UK, 2000; pp. 83-107.

4. Murphy, T.F. Pseudomonas aeruginosa in adults with chronic obstructive pulmonary disease. Curr. Opin. Pulm. Med. 2009, 15, 138-142. [CrossRef] [PubMed]

5. Balasubramanian, D.; Schneper, L.; Kumari, H.; Mathee, K. A dynamic and intricate regulatory network determines Pseudomonas aeruginosa virulence. Nucleic Acids Res. 2012, 41, 1-20. [CrossRef] [PubMed]

6. Reinhart, A.A.; Oglesby-Sherrouse, A.G. Regulation of Pseudomonas aeruginosa Virulence by Distinct Iron Sources. Genes 2016, 7, 126. [CrossRef]

7. Bain, W.; Olonisakin, T.; Yu, M.; Qu, Y.; Hulver, M.; Xiong, Z.; Li, H.; Pilewski, J.; Mallampalli, R.K.; Nouraie, M.; et al. Platelets inhibit apoptotic lung epithelial cell death and protect mice against infection-induced lung injury. Blood Adv. 2019, 3, 432-445. [CrossRef]

8. Rashid, M.H.; Kornberg, A. Inorganic polyphosphate is needed for swimming, swarming, and twitching motilities of Pseudomonas aeruginosa. Proc. Natl. Acad. Sci. USA 2000, 97, 4885-4890. [CrossRef]

9. Bucior, I.; Pielage, J.F.; Engel, J. Pseudomonas aeruginosa Pili and Flagella Mediate Distinct Binding and Signaling Events at the Apical and Basolateral Surface of Airway Epithelium. PLoS Pathog. 2012, 8, e1002616. [CrossRef] 
10. Burrows, L.L. Pseudomonas aeruginosa Twitching Motility: Type IV Pili in Action. Annu. Rev. Microbiol. 2012, 66, 493-520. [CrossRef]

11. Irvin, R.T.; Doig, P.; Lee, K.K.; Sastry, P.A.; Paranchych, W.; Todd, T.; Hodges, R.S. Characterization of the Pseudomonas aeruginosa pilus adhesin: Confirmation that the pilin structural protein subunit contains a human epithelial cell-binding domain. Infect. Immun. 1989, 57, 3720-3726. [CrossRef]

12. Gupta, S.K.; Berk, R.S.; Masinick, S.; Hazlett, L.D. Pili and lipopolysaccharide of Pseudomonas aeruginosa bind to the glycolipid asialo GM1. Infect. Immun. 1994, 62, 4572-4579. [CrossRef]

13. Vallet, I.; Olson, J.W.; Lory, S.; Lazdunski, A.; Filloux, A. The chaperone/usher pathways of Pseudomonas aeruginosa: Identification of fimbrial gene clusters (cup) and their involvement in biofilm formation. Proc. Natl. Acad. Sci. USA 2001, 98, 6911-6916. [CrossRef] [PubMed]

14. Chemani, C.; Imberty, A.; De Bentzmann, S.; Pierre, M.; Wimmerová, M.; Guery, B.; Faure, K. Role of LecA and LecB Lectins in Pseudomonas aeruginosa-Induced Lung Injury and Effect of Carbohydrate Ligands. Infect. Immun. 2009, 77, 2065-2075. [CrossRef] [PubMed]

15. Hayashi, N.; Nishizawa, H.; Kitao, S.; Deguchi, S.; Nakamura, T.; Fujimoto, A.; Shikata, M.; Gotoh, N. Pseudomonas aeruginosainjects type III effector ExoS into epithelial cells through the function of type IV pili. FEBS Lett. 2015, 589, 890-896. [CrossRef] [PubMed]

16. Green, D.R.; Llambi, F. Cell Death Signaling. Cold Spring Harb. Perspect. Biol. 2015, 7. [CrossRef]

17. Kerr, J.F.R.; Wyllie, A.H.; Currie, A.R. Apoptosis: A Basic Biological Phenomenon with Wideranging Implications in Tissue Kinetics. Br. J. Cancer 1972, 26, 239-257. [CrossRef] [PubMed]

18. Galluzzi, L.; Vitale, I.; Abrams, J.M.; Alnemri, E.S.; Baehrecke, E.H.; Blagosklonny, M.V.; Dawson, T.M.; Dawson, V.L.; El-Deiry, W.S.; Fulda, S.; et al. Molecular definitions of cell death subroutines: Recommendations of the Nomenclature Committee on Cell Death 2012. Cell Death Differ. 2011, 19, 107-120. [CrossRef]

19. Paoli, P.; Giannoni, E.; Chiarugi, P. Anoikis molecular pathways and its role in cancer progression. Biochim. Biophys. Acta (BBA) Bioenerg. 2013, 1833, 3481-3498. [CrossRef]

20. Bergsbaken, T.; Fink, S.L.; Cookson, B.T. Pyroptosis: Host cell death and inflammation. Nat. Rev. Genet. 2009, 7, 99-109. [CrossRef]

21. Gong, W.; Shi, Y.; Ren, J. Research progresses of molecular mechanism of pyroptosis and its related diseases. Immunobiology 2020, 225, 151884. [CrossRef]

22. Platnich, J.M.; Muruve, D.A. NOD-like receptors and inflammasomes: A review of their canonical and non-canonical signaling pathways. Arch. Biochem. Biophys. 2019, 670, 4-14. [CrossRef]

23. Jorch, S.K.; Kubes, P. An emerging role for neutrophil extracellular traps in noninfectious disease. Nat. Med. 2017, 23, 279-287. [CrossRef] [PubMed]

24. Dar, H.; Tyurina, Y.Y.; Mikulska-Ruminska, K.; Shrivastava, I.; Ting, H.-C.; Tyurin, V.A.; Krieger, J.; Croix, C.M.S.; Watkins, S.; Bayir, E.; et al. Pseudomonas aeruginosa utilizes host polyunsaturated phosphatidylethanolamines to trigger theft-ferroptosis in bronchial epithelium. J. Clin. Investig. 2018, 128, 4639-4653. [CrossRef] [PubMed]

25. Kagan, V.; Mao, G.; Qu, F.; Angeli, J.P.F.; Doll, S.; Croix, C.S.; Dar, H.H.; Liu, B.; Tyurin, V.A.; Ritov, V.B.; et al. Oxidized arachidonic and adrenic PEs navigate cells to ferroptosis. Nat. Methods 2016, 13, 81-90. [CrossRef] [PubMed]

26. Wenzel, S.E.; Tyurina, Y.Y.; Zhao, J.; Croix, C.M.S.; Dar, H.; Mao, G.; Tyurin, V.A.; Anthonymuthu, T.S.; Kapralov, O.; Amoscato, A.A.; et al. PEBP1 Wardens Ferroptosis by Enabling Lipoxygenase Generation of Lipid Death Signals. Cell 2017, 171, 628-641.e26. [CrossRef] [PubMed]

27. Lei, P.; Bai, T.; Sun, Y. Mechanisms of Ferroptosis and Relations with Regulated Cell Death: A Review. Front. Physiol. 2019, 10. [CrossRef] [PubMed]

28. Brigelius-Flohé, R.; Maiorino, M. Glutathione peroxidases. Biochim. Biophys. Acta (BBA) Gen. Subj. 2013, 1830, 3289-3303. [CrossRef]

29. Yang, W.S.; SriRamaratnam, R.; Welsch, M.E.; Shimada, K.; Skouta, R.; Viswanathan, V.; Cheah, J.H.; Clemons, P.A.; Shamji, A.F.; Clish, C.; et al. Regulation of ferroptotic cancer cell death by GPX4. Cell 2014, 156, 317-331. [CrossRef] 
30. Dixon, S.J.; Winter, G.E.; Musavi, L.S.; Lee, E.D.; Snijder, B.; Rebsamen, M.; Superti-Furga, G.; Stockwell, B.R. Human Haploid Cell Genetics Reveals Roles for Lipid Metabolism Genes in Nonapoptotic Cell Death. ACS Chem. Biol. 2015, 10, 1604-1609. [CrossRef]

31. Yang, W.S.; Kim, K.J.; Gaschler, M.M.; Patel, M.; Shchepinov, M.S.; Stockwell, B.R. Peroxidation of polyunsaturated fatty acids by lipoxygenases drives ferroptosis. Proc. Natl. Acad. Sci. USA 2016, 113, E4966-E4975. [CrossRef]

32. Doll, S.; Proneth, B.; Tyurina, Y.Y.; Panzilius, E.; Kobayashi, S.; Ingold, I.; Irmler, M.; Beckers, J.; Aichler, M.; Walch, A.; et al. ACSL4 dictates ferroptosis sensitivity by shaping cellular lipid composition. Nat. Methods 2016, 13, 91-98. [CrossRef]

33. Shintoku, R.; Takigawa, Y.; Yamada, K.; Kubota, C.; Yoshimoto, Y.; Takeuchi, T.; Koshiishi, I.; Torii, S. Lipoxygenase-mediated generation of lipid peroxides enhances ferroptosis induced by erastin and RSL3. Cancer Sci. 2017, 108, 2187-2194. [CrossRef] [PubMed]

34. Toyokuni, S.; Ito, F.; Yamashita, K.; Okazaki, Y.; Akatsuka, S. Iron and thiol redox signaling in cancer: An exquisite balance to escape ferroptosis. Free Radic. Biol. Med. 2017, 108, 610-626. [CrossRef] [PubMed]

35. Shah, R.; Shchepinov, M.S.; Pratt, D.A. Resolving the Role of Lipoxygenases in the Initiation and Execution of Ferroptosis. ACS Central Sci. 2018, 4, 387-396. [CrossRef] [PubMed]

36. Nirmala, J.G.; Lopus, M. Cell death mechanisms in eukaryotes. Cell Biol. Toxicol. 2019, 36, 145-164. [CrossRef] [PubMed]

37. Grassmé, H.; Jendrossek, V.; Gulbins, E. Molecular mechanisms of bacteria induced apoptosis. Apoptosis 2001, 6, 441-445. [CrossRef] [PubMed]

38. Grassmé, H. CD95/CD95 Ligand Interactions on Epithelial Cells in Host Defense to Pseudomonas aeruginosa. Science 2000, 290, 527-530. [CrossRef]

39. Valente, E.; Assis, M.C.; Alvim, I.M.; Pereira, G.M.; Plotkowski, M.C. Pseudomonas aeruginosa induces apoptosis in human endothelial cells. Microb. Pathog. 2000, 29, 345-356. [CrossRef]

40. Aballay, A.; Ausubel, F.M. Programmed cell death mediated by ced-3 and ced-4 protects Caenorhabditis elegans from Salmonella typhimurium-mediated killing. Proc. Natl. Acad. Sci. USA 2001, 98, 2735-2739. [CrossRef]

41. Maurice, N.M.; Bedi, B.; Yuan, Z.; Goldberg, J.B.; Koval, M.; Hart, C.M.; Sadikot, R.T. Pseudomonas aeruginosa Induced Host Epithelial Cell Mitochondrial Dysfunction. Sci. Rep. 2019, 9, 1-15. [CrossRef]

42. Song, D.; Meng, J.; Cheng, J.; Fan, Z.; Chen, P.; Ruan, H.; Tu, Z.; Kang, N.; Li, N.; Xu, Y.; et al. Pseudomonas aeruginosa quorum-sensing metabolite induces host immune cell death through cell surface lipid domain dissolution. Nat. Microbiol. 2018, 4, 97-111. [CrossRef]

43. Losa, D.; Köhler, T.; Bellec, J.; Dudez, T.; Crespin, S.; Bacchetta, M.; Boulanger, P.; Hong, S.S.; Morel, S.; Nguyen, T.H.; et al. Pseudomonas aeruginosa-Induced Apoptosis in Airway Epithelial Cells Is Mediated by Gap Junctional Communication in a JNK-Dependent Manner. J. Immunol. 2014, 192, 4804-4812. [CrossRef]

44. Ryu, J.-C.; Kim, M.-J.; Kwon, Y.; Oh, J.-H.; Yoon, S.S.; Shin, S.J.; Yoon, J.-H.; Ryu, J.-H. Neutrophil pyroptosis mediates pathology of P. aeruginosa lung infection in the absence of the NADPH oxidase NOX2. Mucosal Immunol. 2016, 10, 757-774. [CrossRef] [PubMed]

45. Pylaeva, E.; Lang, S.; Jablonska, J. The Essential Role of Type I Interferons in Differentiation and Activation of Tumor-Associated Neutrophils. Front. Immunol. 2016, 7. [CrossRef]

46. González-Navajas, J.M.; Lee, J.; David, M.; Raz, E. Immunomodulatory functions of type I interferons. Nat. Rev. Immunol. 2012, 12, 125-135. [CrossRef] [PubMed]

47. Parker, D.; Cohen, T.S.; Alhede, M.; Harfenist, B.S.; Martin, F.J.; Prince, A. Induction of Type I Interferon Signaling by Pseudomonas aeruginosa Is Diminished in Cystic Fibrosis Epithelial Cells. Am. J. Respir. Cell Mol. Biol. 2012, 46, 6-13. [CrossRef]

48. Pylaeva, E.; Bordbari, S.; Spyra, I.; Decker, A.S.; Häussler, S.; Vybornov, V.; Lang, S.; Jablonska, J. Detrimental Effect of Type I IFNs During Acute Lung Infection With Pseudomonas aeruginosa Is Mediated Through the Stimulation of Neutrophil NETosis. Front. Immunol. 2019, 10, 2190. [CrossRef] [PubMed]

49. Khan, M.A.; Philip, L.M.; Cheung, G.; Vadakepeedika, S.; Grasemann, H.; Sweezey, N.; Palaniyar, N. Regulating NETosis: Increasing pH Promotes NADPH Oxidase-Dependent NETosis. Front. Med. 2018, 5. [CrossRef] 
50. Shafikhani, S.H.; Morales, C.; Engel, J. The Pseudomonas aeruginosa type III secreted toxin ExoT is necessary and sufficient to induce apoptosis in epithelial cells. Cell. Microbiol. 2008, 10, 994-1007. [CrossRef] [PubMed]

51. Wood, S.; Goldufsky, J.; Shafikhani, S.H. Pseudomonas aeruginosa ExoT Induces Atypical Anoikis Apoptosis in Target Host Cells by Transforming Crk Adaptor Protein into a Cytotoxin. PLoS Pathog. 2015, 11, e1004934. [CrossRef]

52. Wood, S.J.; Goldufsky, J.W.; Bello, D.; Masood, S.; Shafikhani, S.H. Pseudomonas aeruginosaExoT Induces Mitochondrial Apoptosis in Target Host Cells in a Manner That Depends on Its GTPase-activating Protein (GAP) Domain Activity. J. Biol. Chem. 2015, 290, 29063-29073. [CrossRef]

53. Scannapieco, F.; Wang, B.; Shiau, H.J. Oral Bacteria and Respiratory Infection: Effects on Respiratory Pathogen Adhesion and Epithelial Cell Proinflammatory Cytokine Production. Ann. Periodontol. 2001, 6, 78-86. [CrossRef] [PubMed]

54. Pan, Y.; Teng, D.; Burke, A.C.; Haase, E.; Scannapieco, F. Oral bacteria modulate invasion and induction of apoptosis in HEp-2 cells by Pseudomonas aeruginosa. Microb. Pathog. 2009, 46, 73-79. [CrossRef]

55. Torres, I.M.; Demirdjian, S.; Vargas, J.; Goodale, B.C.; Berwin, B. Acidosis increases the susceptibility of respiratory epithelial cells to Pseudomonas aeruginosa-induced cytotoxicity. Am. J. Physiol. Cell. Mol. Physiol. 2017, 313, L126-L137. [CrossRef] [PubMed]

56. Ma, A.; Boone, D.L.; Lodolce, J.P. The Pleiotropic Functions of Interleukin 15. J. Exp. Med. 2000, 191, $753-756$. [CrossRef]

57. Fehniger, T.A.; Caligiuri, M.A. Interleukin 15: Biology and relevance to human disease. Blood 2001, 97, 14-32. [CrossRef] [PubMed]

58. Li, X.C.; Demirci, G.; Ferrari-Lacraz, S.; Groves, C.; Coyle, A.; Malek, T.R.; Strom, T.B. IL-15 and IL-2: A matter of life and death for T cells in vivo. Nat. Med. 2001, 7, 114-118. [CrossRef] [PubMed]

59. Waldmann, T.A. The biology of interleukin-2 and interleukin-15: Implications for cancer therapy and vaccine design. Nat. Rev. Immunol. 2006, 6, 595-601. [CrossRef] [PubMed]

60. Lucas, M.; Schachterle, W.; Oberle, K.; Aichele, P.; Diefenbach, A. Dendritic Cells Prime Natural Killer Cells by trans-Presenting Interleukin 15. Immunity 2007, 26, 503-517. [CrossRef] [PubMed]

61. Inoue, S.; Unsinger, J.; Davis, C.G.; Muenzer, J.T.; Ferguson, T.A.; Chang, K.; Osborne, D.F.; Clark, A.T.; Coopersmith, C.M.; McDunn, J.E.; et al. IL-15 prevents apoptosis, reverses innate and adaptive immune dysfunction, and improves survival in sepsis. J. Immunol. 2009, 184, 1401-1409. [CrossRef]

62. Kennedy, M.K.; Glaccum, M.; Brown, S.N.; Butz, E.A.; Viney, J.L.; Embers, M.; Matsuki, N.; Charrier, K.; Sedger, L.M.; Willis, C.R.; et al. Reversible Defects in Natural Killer and Memory Cd8 T Cell Lineages in Interleukin 15-Deficient Mice. J. Exp. Med. 2000, 191, 771-780. [CrossRef]

63. Ma, A.; Koka, R.; Burkett, P. DIVERSE FUNCTIONS OF IL-2, IL-15, AND IL-7 IN LYMPHOID HOMEOSTASIS. Annu. Rev. Immunol. 2006, 24, 657-679. [CrossRef]

64. Maeurer, M.; Trinder, P.; Hommel, G.; Walter, W.; Freitag, K.; Atkins, D.; Storkel, S. Interleukin-7 or Interleukin-15 Enhances Survival of Mycobacterium tuberculosis-Infected Mice. Infect. Immun. 2000, 68, 2962-2970. [CrossRef] [PubMed]

65. Motegi, A.; Kinoshita, M.; Inatsu, A.; Habu, Y.; Saitoh, D.; Seki, S. IL-15-induced CD8+CD122+T cells increase antibacterial and anti-tumor immune responses: Implications for immune function in aged mice. J. Leukoc. Biol. 2008, 84, 1047-1056. [CrossRef]

66. Hiromatsu, T.; Yajima, T.; Matsuguchi, T.; Nishimura, H.; Wajjwalku, W.; Arai, T.; Nimura, Y.; Yoshikai, Y. Overexpression of Interleukin-15 Protects againstEscherichia coli-Induced Shock Accompanied by Inhibition of Tumor Necrosis Factor- $\alpha$-Induced Apoptosis. J. Infect. Dis. 2003, 187, 1442-1451. [CrossRef] [PubMed]

67. Zou, C.; Li, J.; Xiong, S.; Chen, Y.; Wu, Q.; Li, X.; Weathington, N.M.; Han, S.H.; Snavely, C.; Chen, B.B.; et al. Mortality factor 4 like 1 protein mediates epithelial cell death in a mouse model of pneumonia. Sci. Transl. Med. 2015, 7, 311ra171. [CrossRef]

68. Shi, X.; Wei, W.; Wang, N. Tremella polysaccharides inhibit cellular apoptosis and autophagy induced by Pseudomonas aeruginosa lipopolysaccharide in A549 cells through sirtuin 1 activation. Oncol. Lett. 2018, 15, 9609-9616. [CrossRef] [PubMed] 
69. Wu, C.; Chen, X.; Cai, Y.; Xia, J.; Zhou, X.; Xu, S.; Huang, H.; Zhang, L.; Zhou, X.; Du, C.; et al. Risk Factors Associated With Acute Respiratory Distress Syndrome and Death in Patients With Coronavirus Disease 2019 Pneumonia in Wuhan, China. JAMA Intern. Med. 2020. [CrossRef] [PubMed]

70. Chen, N.; Zhou, M.; Dong, X.; Qu, J.; Gong, F.; Han, Y.; Qiu, Y.; Wang, J.; Liu, Y.; Wei, Y.; et al. Epidemiological and clinical characteristics of 99 cases of 2019 novel coronavirus pneumonia in Wuhan, China: A descriptive study. Lancet 2020, 395, 507-513. [CrossRef]

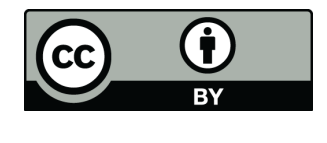

(C) 2020 by the authors. Licensee MDPI, Basel, Switzerland. This article is an open access article distributed under the terms and conditions of the Creative Commons Attribution (CC BY) license (http://creativecommons.org/licenses/by/4.0/). 